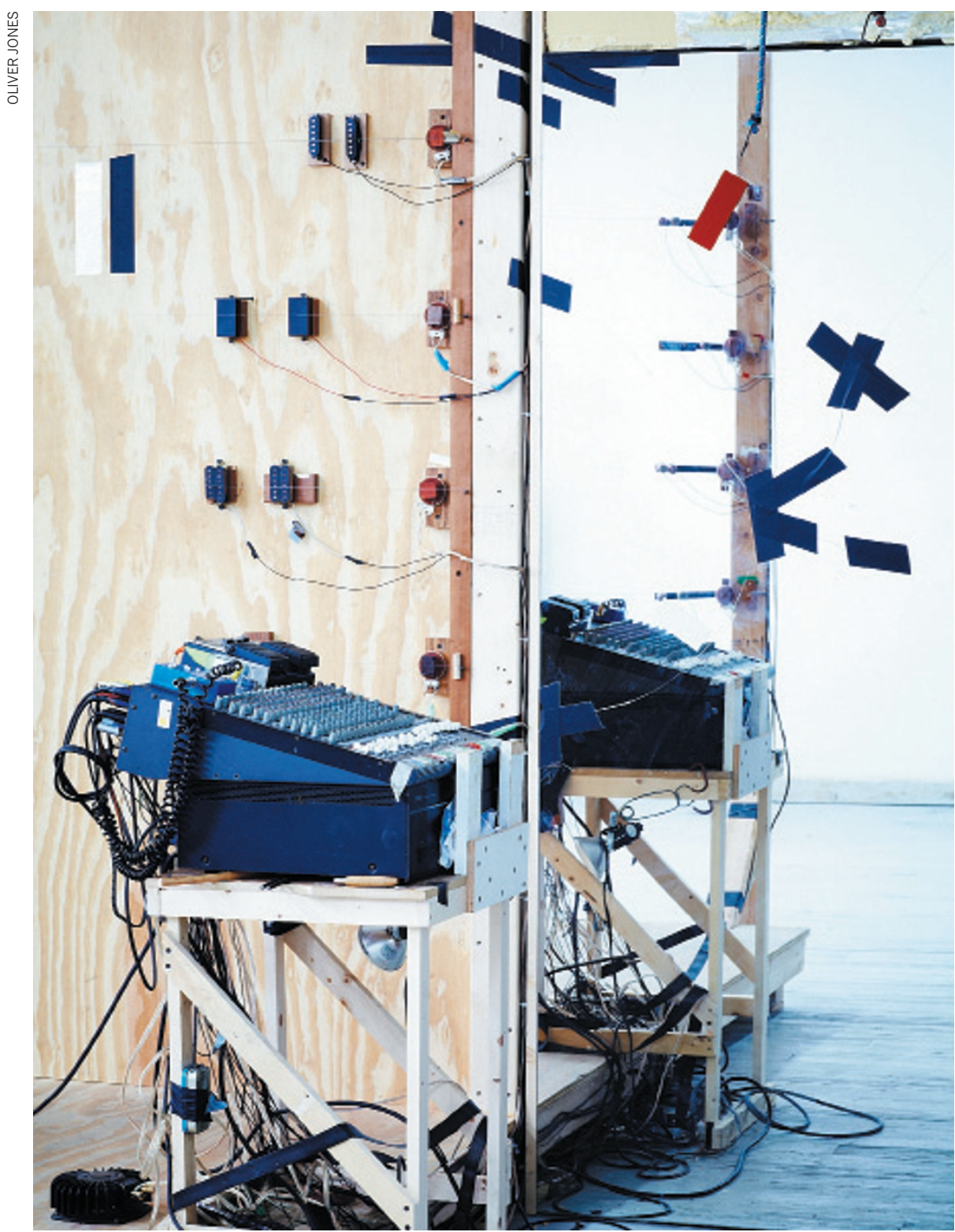

Part of an instrument built with artist Oliver Jones to create sounds in Composing the Tinnitus Suites.

\title{
Tinnitus tunesmith
}

Sound artist Daniel Fishkin tries to convey the experience of tinnitus. As the latest incarnation of his installation series Composing the Tinnitus Suites opens in Brooklyn, New York, he talks about building a mechanical model of the inner ear.

\section{How did your tinnitus begin?}

It started in 2008. I was 22, and it was the evening of my senior recital in music composition at Bard College [in Annandale-onHudson, New York]. The concert was not loud, but afterwards I could hear a highpitched sound. I had my ears tested over and over. Doctors told me to get used to it, but habituation is not always possible. People with tinnitus can experience depression; some have been driven to suicide.

What you have learned about the condition? The mechanics of tinnitus are still poorly understood. Mine is likely to be from noise exposure, but it also occurs as a result of skull fractures and brain tumours, and as a side effect of common drugs. No treatments
I was prescribed have helped. I haven't had access to experimental treatments such as [repetitive] transcranial magnetic stimulation. Because there is currently no way to regrow damaged sensory hair cells in the human cochlea, there is no cure for me.

\section{How did this affect your music?}

I tried to keep composing, but it was impossible. So I began to study

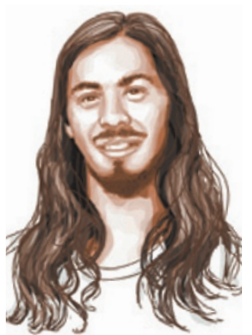

Composing the Tinnitus Suites DANIEL FISHKIN Nothing Space, Brooklyn, New York. On 24, 25 and

31 January and 1,8 and 9 February. circuitry and engineering, and built a large sculpture strung with 6-metre-long piano strings wired in a feedback loop that made gorgeous long crescendos. I didn't realize until I showed the device to Tricia MacKenzie, a neuroscientist who studies hearing loss, that I had made a giant mechanical model of the inner ear. It became the first installation in my ongoing project, Composing the Tinnitus Suites (see go.nature.com/xhvyu9).

\section{Tell me about your next installation in this} project.

This month I will create a new musical sculpture at the Nothing Space in Brooklyn. I will line the walls of the gallery with piano wire so that when the audience enters, they will be walking inside the instrument. There will be six performances that will integrate the sustained sounds of my instrument with woodwind and drums.

\section{Are you trying to reproduce your experience} of tinnitus?

My sculptures generate tones that drift slowly like those in my head, but because my tinnitus is not an acoustic phenomenon - it is a perceived sound rather than actual sound waves - I have found that it is impossible to reproduce the sound. For inspiration, I have tried to enhance the ringing in my ears by listening to loud tones for long periods of time, and consuming substances such as aspirin, caffeine and quinine, which are toxic to the ear.

\section{How will the project continue?}

The crux of the work is human agency. I want to connect people with tinnitus, give doctors a sense of what their patients are going through, and start a conversation between musicians and scientists. This piece will go on as long my ears ring. Instead of trying to get rid of the ringing, I am now asking: what if, instead of a curse, tinnitus is a kind of superpower? 